
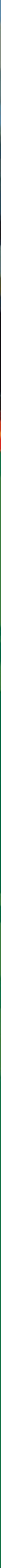


\section{Enhancing resilience and reducing vulnerability: Lessons learned from past disasters}

\section{David King}

Learning from the reality of disasters that have been experienced or which have been learned vicariously from the experience of other people and communities, empowers people to reduce their vulnerability and to enhance their resilience in the face of catastrophe. Unfortunately the process of learning is neither as obvious nor as commonsense as the drama and tragedy of an unfolding disaster demands. Lessons are not fully learned, the missing details may become fatal flaws in people's understanding of events, and reconstruction of events from the perspectives of participants, observers and analysts are necessarily piecemeal, driven by drama, economy and politics, un-contextualised and unique. Learning from past disasters is not a simple or obvious process. This chapter begins with reflections on perception; scale; emphasis; and place, in order to understand some of the diversity of disaster learning experiences. Examples of lessons learned from local, regional and distant disasters provide a review in order to identify issues, commonalities (within unique events) and those mitigative actions that may reduce each person's and each community's vulnerability to a range of hazards, and simultaneously enhance their resilience before, during and after a catastrophic event.

Do communities or individuals learn anything from the experience of the disaster? Is vulnerability to future events reduced by direct experience or indirectly experiencing disaster, and/or is resilience enhanced? The Integrated Emergency Management System model of Prevention, Preparedness, Response and Recovery assumes a continual feedback loop. Emergency managers are required to learn from each disaster through debriefing, studies, reorganisation, and redefinition of priorities.

Many lessons learned for communities by emergency managers are passed down to communities through education, warnings, information, mitigation, physical prevention structures, planning and intervention. Emergency managers, as professionals, have a more global view and their job of 
protecting communities is to learn lessons from all disasters in order to improve mitigation and capacity to respond and to aid recovery.

The problem for emergency managers in indirectly learning from other disasters is that experience comes second hand from other participants and must then be processed, redefined, understood and transmitted third hand to communities for which they are responsible. At the same time individuals and communities learn of other disaster experiences primarily through the media, and sort information and structure other people's experiences to fit their own situation and place. This process at community level is much more piecemeal than that of emergency management. However, it is also location and situation specific, whereas the emergency managers' sorting and understanding of others' experiences is directed to responsibility for many communities - the whole state, or nation, or even an international region. Thus at the initial level of learning indirectly from other communities' disasters and experiences, there are two radically different learning experiences. The emergency manager's learned experience is top-down and global, while the community's is bottom-up and personal.

\section{Post-disaster Studies}

The first stages of a disaster response require rapid appraisals to assess needs and response levels. Needs analyses inevitably form part of the briefings and may contribute to deeper reflections and lessons that can be learned, especially at the organisational level. However their primary function is to satisfy immediate needs under pressure. Researchers are often not involved at this initial stage. Researchers usually visit the scene of a disaster within a few days, or up to a week or so, after an event. The aim is to keep out of the way of response teams, and researchers do not enter a declared disaster area until they have been granted permission from the authorities who are primarily involved in response and relief. The aim of the post-disaster research is to record issues, experiences and impacts, while these are fresh in people's minds. These studies are also primarily records of what happened in an event, but they form the first stage of attempting to analyse issues and ultimately to synthesise disaster experiences into more general conclusions that can inform policy.

Enormous numbers of post-disaster studies and reports are available, ranging from measurements of purely physical impacts to records of highly personal human experiences. For tropical cyclones and hurricanes alone, Haig (2004) brought together over 200 studies into a web site International Post Cyclone Database. This database cross references individual studies according to their titles, keywords, survey aims, type, study area, methodology, key findings, events name, date, location, cities, states and 
countries. As further events are added, comparisons of issues impacts and experiences are enhanced.

A review of 130 post-disaster studies (King, 2002) summarised places, events, types of disasters and classified their methods. As the USA and Australia had funding programs for post-disaster surveys, the majority of these reports were written by USA and Australian researchers although because US-based research could obtain funding to examine overseas disasters, many studies of events in other parts of the world had been carried out by US-based researchers. Of the 130 studies that were examined, 29 were cyclones/hurricanes, 21 were floods and 13 earthquakes, with eight bushfires and nine tornadoes. These were the dominant disasters in a list that also covered human induced hazards. These five hazard groups are the major killers, but to an extent are predictable, with appropriate behaviour and preparatory actions that can be taken to reduce vulnerability and impact. As these were all post-disaster studies they were all consequently case studies of specific events, occasionally more than one, but primarily concerned with a single disaster on those issues related to a place and time.

Members of the Centre for Disaster Studies carried out a series of post disaster studies between 1997 and 2006 covering 16 separate disasters in 20 different locations (see Table 3.1). With the exception of the Indian Ocean Tsunami and human induced disasters like the Bali bombing, all were floods and cyclones and in particular the events were concentrated in local communities.

The first event in Table 3.1 below, Cyclone Gillian, was a non event but a warning to the Bureau of Meteorology about the lack of preparation. No warning had been issued to a major Queensland urban area since the beginning of the decade. This category one cyclone dissipated before reaching the coast, however, it occurred in the middle of a working day and the experience illustrated chaos in the manner in which schools and workplaces were closed down as well as a general lack of preparation.

Two much later studies took up a related theme of severe category 5 cyclone warnings in communities that subsequently were spared impact or received much less impact than expected. In 2005 Cyclone Ingrid crossed Cape York Peninsula but missed all the communities it had threatened and in 2006 Cyclone Monica crossed the Peninsula and deepened into a very severe category 5 as it skirted the Northern Territory. Monica weakened to a category 3 when it finally crossed over Darwin. Surveys targeted people's attitudes to preparing for the worst and not going through it, the 'cry wolf' syndrome. Research showed a high level of tolerance for being fully warned. 


\section{A Litany of Disasters}

Table 3.1 Post-disaster studies carried out by the Centre for Disaster Studies, 1997-2006

\begin{tabular}{|c|c|c|c|c|}
\hline Place & Year & Hazard & Name & Research Method \\
\hline Townsville & 1997 & Cyclone & Gillian & $\begin{array}{l}\text { Questionnaire, } \\
\text { warnings \& behaviour }\end{array}$ \\
\hline Cloncurry & 1997 & Flood & & $\begin{array}{l}\text { Questionnaire, } \\
\text { interviews }\end{array}$ \\
\hline Cairns & \multirow{3}{*}{1997} & \multirow{3}{*}{ Cyclone } & \multirow{3}{*}{ Justin } & \multirow{3}{*}{$\begin{array}{l}\text { Longitudinal } \\
\text { questionnaire \& short } \\
\text { survey questionnaire }\end{array}$} \\
\hline Mareeba & & & & \\
\hline Innisfail & & & & \\
\hline Townsville & 1998 & Floods & $\begin{array}{l}\text { (ex-Cyclone } \\
\text { Syd) }\end{array}$ & $\begin{array}{l}\text { Household telephone, } \\
\text { business \& Magnetic } \\
\text { Island surveys } \\
\text { interviews }\end{array}$ \\
\hline Burketown & \multirow{3}{*}{1998} & \multirow{3}{*}{ Floods } & & \multirow{3}{*}{$\begin{array}{l}\text { Questionnaire, } \\
\text { interviews }\end{array}$} \\
\hline Normanton & & & & \\
\hline Karumba & & & & \\
\hline Innisfail & \multirow{4}{*}{1999} & \multirow{4}{*}{ Cyclone } & \multirow{4}{*}{ Rona } & $\begin{array}{l}\text { Flooded buildings } \\
\text { survey }\end{array}$ \\
\hline $\begin{array}{l}\text { Cairns - Barron River } \\
\text { suburbs }\end{array}$ & & & & $\begin{array}{l}\text { Evacuation } \\
\text { questionnaire }\end{array}$ \\
\hline $\begin{array}{l}\text { Port Douglas \& } \\
\text { Mosman }\end{array}$ & & & & $\begin{array}{l}\text { Warnings \& behaviour } \\
\text { questionnaire }\end{array}$ \\
\hline Wujal Wujal & & & & $\begin{array}{l}\text { Warnings \& impact } \\
\text { interviews }\end{array}$ \\
\hline Broome & 2000 & Cyclone & Rosita & $\begin{array}{l}\text { Questionnaire, } \\
\text { interviews }\end{array}$ \\
\hline Cairns & 2000 & Cyclone & Steve & $\begin{array}{l}\text { Longitudinal } \\
\text { questionnaire }\end{array}$ \\
\hline Mornington Island & 2001 & Cyclone & Abigail & $\begin{array}{l}\text { Questionnaire, } \\
\text { interviews }\end{array}$ \\
\hline Sierra Leone & 2002 & Civil War & & $\begin{array}{l}\text { Interviews, meetings, } \\
\text { secondary data }\end{array}$ \\
\hline$\overline{\text { Bali }}$ & 2003 & Terrorism & & $\begin{array}{l}\text { Interviews, meetings, } \\
\text { secondary data }\end{array}$ \\
\hline Tikopia, Solomons & 2003 & Cyclone & Zoe & Basic needs \\
\hline Anuta, Solomons & & & & assessment \\
\hline Phuket, Thailand & 2005 & Tsunami & Indian $\quad$ Ocean & Interviews, \\
\hline Maldives & & & tsunami & $\begin{array}{l}\text { observations, field } \\
\text { measurements, } \\
\text { secondary data }\end{array}$ \\
\hline Port Douglas & 2005 & Cyclone & Ingrid & $\begin{array}{l}\text { Interviews, } \\
\text { questionnaire }\end{array}$ \\
\hline $\begin{array}{lrl}\text { Innisfail \& } & \text { nearby } \\
\text { communities } & \\
\end{array}$ & 2006 & Cyclone & Larry & $\begin{array}{l}\text { Interviews, } \\
\text { questionnaire }\end{array}$ \\
\hline Darwin & 2006 & Cyclone & Monica & Telephone survey \\
\hline
\end{tabular}


Centre for Disaster Studies researcher, Anderson-Berry, focussed on the northern beaches of Cairns during 1996 to measure cyclone awareness and preparedness in a community that had not experienced a cyclone threat for six years. In 1997 the giant Cyclone J ustin, filled the Coral Sea and took a month before finally crossing the Cairns northern beaches coast line as a category 2 . This was an opportunity to resurvey experience and behaviour amongst the same population that had completed the awareness and preparedness survey only six months earlier. Making this a truly longitudinal study, category 2 Cyclone Steve in 2000 passed over the same communities (Anderson-Berry \& King, 2005). A high proportion of residents who had taken part in the earlier surveys were still available to participate in the third study, providing a valuable measure of a small but significant increase in community awareness and preparedness.

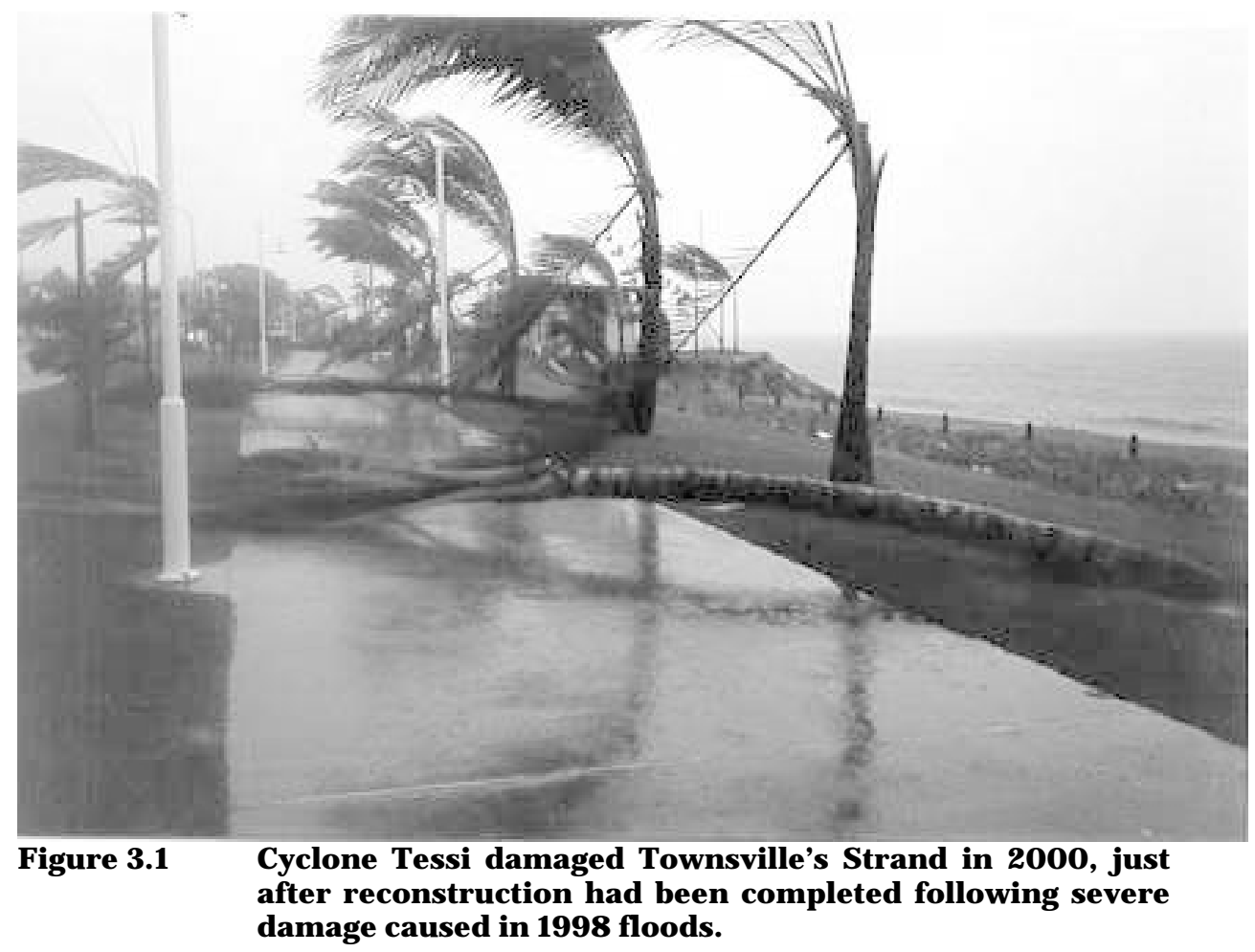

Other cyclones provided further opportunities to pursue awareness and preparedness, but also to examine issues of warnings and hazard perceptions. Cyclone Abigail in 2001 was only a category two, but it passed over a low-lying Indigenous community at Mornington Island, where Eddie McLachlan, a Centre for Disaster Studies researcher was already recording indigenous hazard knowledge. J ust as this study was oriented to a particular emphasis, similarly Cyclone Rosita at Broome in 2000 was an opportunity to 
concentrate on an issue, by looking at the impact on a tourist location. The vulnerability of tourists and tourist destinations has developed as a major research area for the Centre, not just because of its significance on the Queensland coast but principally because of the lack of crisis management in the tourist industry.

In 1999, Cyclone Rona initiated a series of issues. Post-disaster studies following the passage of this exceptionally wet cyclone addressed different issues in locations that were over $200 \mathrm{~km}$ apart. This cyclone was preceded and accompanied by flooding rains and crossed the coast at Cow Bay in the Daintree rainforest. Wujal Wujal and Bloomfield communities to the north (around 1000 Indigenous and Non-indigenous residents) were totally isolated for weeks and failed to notice formal warnings of the close proximity of the cyclone. Anderson-Berry's initial visit to the community was followed by a series of studies as researchers in the Centre directed emphasis to remote and Indigenous communities, examining their vulnerability, resilience and warnings. South of Cyclone Rona's eye, Douglas Shire was fairly well-prepared but the controversial issue was the efficacy of warnings. The post-disaster surveys in Port Douglas and Mosman were concerned with this issue of official warnings and their effectiveness. While the survey at that time showed a satisfactory level of awareness and preparedness, a similar kind of survey was carried out in the same locations in 2005 after category 5 Cyclone Ingrid had passed (ultimately crossing Cape York Peninsula but causing very little damage). In this case the survey was carried out for the opposite purpose of eliciting community response to what the media had termed a 'false alarm'. Community attitudes towards their preparations were positive, as it should be, but the issue of false alarm perceptions remains a concern to emergency managers.

Cyclone Rona's passage dumped vast amounts of rain on the Atherton Tablelands to the west of Cairns, causing the Barron River to flood. This river emerges from the mountain range on to the coastal plain of Cairns adjacent to the suburbs of Lake Placid and Caravonica. As the river rose rapidly, authorities issued an evacuation order to all residents of these two suburbs during the middle of the night. The post-disaster survey in Cairns was therefore a detailed questionnaire issued to all households that had evacuated, to record their problems, perceptions and experiences. Of value to the Cairns City Council, which had not previously conducted an evacuation, the survey also illustrated the controversial issue of pets in evacuation centres. More than $80 \%$ of households took pets with them, from cats and dogs to some truly bizarre creatures. As a consequence the Cairns City Council followed up the pets issue in council surveys that were carried out during 2004. 
The fourth of the Cyclone Rona studies also concentrated on flood experiences in Innisfail, $90 \mathrm{~km}$ south of Cairns, where houses and commercial properties in low-lying areas adjacent to the Johnstone River were inundated. The survey stressed property damage and loss related directly to house type (especially low or high set) and measured precise flood levels on property and within buildings.

Cyclone Larry in March 2006 was in a sense 'the big one' that had been feared for many years, but it just missed a coastal city (either Cairns or Townsville could have been severely impacted upon). Once again it was Innisfail that was the victim along with surrounding small communities and villages on the coastal plain and on the Atherton Tableland. This impact area experienced a category 5 that rapidly weakened to a 4 but remained a severe 4 until it had passed the Tableland. Although a rural area, the affected population of more than 50,000 people was scattered through many small towns and communities. The lesson learned from household surveys was of a well prepared, experienced and knowledgeable community that behaved correctly and consequently experienced no loss of life and few injuries.

Many floods in northern Australia are related to cyclonic weather systems, but there were significant differences in the three sets of post-flood surveys. At Cloncurry in 1997 the Cloncurry River rose rapidly to unprecedented levels, inundating parts of the town, thereby forcing the evacuation of people and property. The Gulf of Carpentaria lowland floods the following year inundated a vast area, as the great rivers that drain into the Gulf coalesced into an inland sea. Towns and communities in the region became islands with problems and issues that emanated from their isolation: lack of food; inundation of septic systems; loss of power and freshwater; a strong risk of secondary disease and infection; and widespread destruction of roads, drainage, bridges and culverts. Most remote cattle stations have traditionally stocked up on provisions for the isolation of the wet season but the predominantly Indigenous small towns and Aboriginal communities lack that capacity. Most households have low incomes, high dependency on welfare and are unable to stockpile supplies. Because of this characteristic of the market, retailers are also restricted in their ability to stock up. Despite these problems these isolated communities were remarkably resilient. The communities endured and made do with what they had available.

Stoic endurance is easily attributed to the social construction of the outback community. Certainly post-disaster studies undertaken by the Centre illustrated many examples of the term 'outback spirit'. However, the same spirit of neighbourliness was equally evident in Townsville during the 1998 flood. This was an extreme rain event (a consequence of a decayed cyclone, in which over $700 \mathrm{~mm}$ of rain fell in less than 24 hours) with creek flash 
flooding causing severe damage in a small number of locations. While carrying out a 1000 household telephone survey in the days following the flood, interviewers recorded many remarkable anecdotes of bravery and selflessness, as well as some of the problems of inappropriate behaviour.

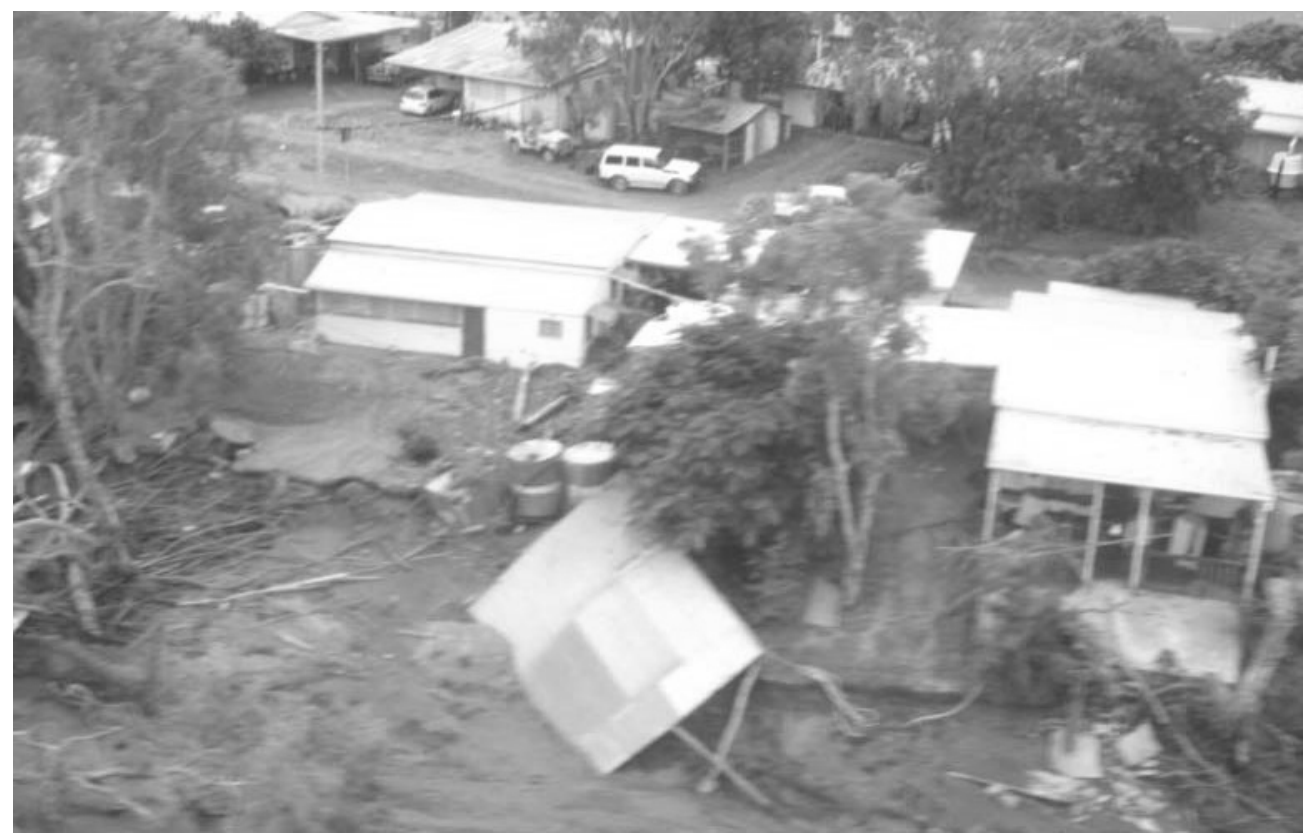

Figure 3.2 Damage to the Black River settlement in Thuringowa following floods in 1998.

Despite having used a variety of research methods and approaches these mainly local events involving predictable and regular hazards of flood and cyclone demonstrated some general trends and impacts.

The following general trends and impacts have been noted:

- unequal distribution of the hazard impact;

- $\quad$ loss of essential services during and for a period after the hazard event;

- $\quad$ lack of expectation in the community of the severity of the impact;

- $\quad$ late or minimal preparation for the hazard;

- response and assistance within the community and between neighbours;

- confusion concerning warnings, and especially the way in which they were portrayed and transmitted by the media;

- a level of resilience which involved acceptance of the hazard and generally a lack of attribution of serious blame. 
This idea of acceptance of natural hazards was expressed by a Thai informant in Phuket during the week following the Indian Ocean Tsunami in 2004 that it was easier in an emotional or psychological sense to deal with natural hazards rather than terror. This sentiment encapsulates an aspect of community resilience that to some extent accepts natural hazards as part of the natural order, something over which little control is possible. War and terror on the other hand undermine people's faith in human nature, threaten all of our humanity and may even be a direct physical threat.

Immediate post-tsunami disaster observations in Thailand also suggested lessons that can be learned from the devastation which could be applied directly to other hazards and other areas, such as coastal Australia (King \& Gurtner, 2005). Tsunami damage resembled many aspects of storm surge damage.

The immediate response to the tsunami in many parts of the world was a transfer and internalisation of the threat. While tsunamis may occur in many parts of the world's plate boundaries, cyclones and hurricanes are much more regular an occurrence, with the storm surge accompanying a severe storm being just as destructive as a tsunami albeit over a longer period of time and with a greater opportunity for evacuation.

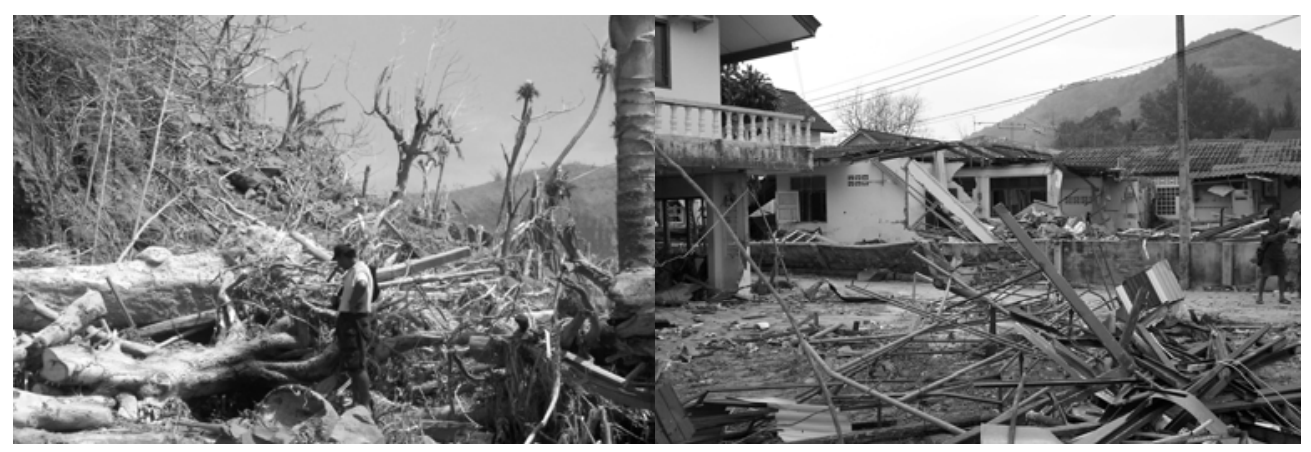

Figure 3.3 Storm surge damage at Tikopia Solomon Islands, left, and tsunami damage at Phuket Thailand, right.

Other significant transfers of the tsunami experience relate to the vulnerability of critical infrastructure and lifelines. Particularly noticeable on Phuket was the lack of damage to significant infrastructure, with response coming from the intact and functioning administrative centre. Recovery was able to progress rapidly despite widespread destruction in the coastal zone. This would probably not be the case in Australian coastal settlements where far too much of the critical infrastructure, economy and services are in low lying or coastal locations. Land use planning and building structure locations were identified as significant issues for post-tsunami mitigation. 
Similarly in Australia there are many people in the community who oppose development along coastal foreshores because of the extreme vulnerability of this zone to storm surge. As the primary tourist resource is the beach and the sea, it is inevitable that pressure for development on the foreshore will continue to come from the tourist industry, whether in Thailand or northern Australia. The Indian Ocean tsunami caused particularly severe damage to small buildings on the foreshore, a lesson that is directly transferable to residential absolute beach frontage.

In Thailand the impact of the tsunami was felt particularly strongly in the tourist industry, tourists themselves and tourist workers. Tourists have often been omitted from community hazard mitigation efforts and yet they are especially vulnerable. The need for hazard education was highlighted by the tsunami. Education needs to be targeted to diverse communities, including tourists and tourism operators as separate identifiable communities. Warning systems for both tsunamis and cyclones can only be effective if communities are educated to understand what the warning means and how to behave.

\section{Hazard Experience and Emergency Management}

There are common themes in emergency managers' and researchers' perspectives on the lessons that can be learned from disasters. There are also common patterns and processes that are identified in similar types of disasters. Yet while a particular level of flood, category of cyclone or scale of earthquake may demonstrate similar processes, the resulting disasters are all different. Location, culture, society, politics, organisation, awareness and many other factors all contribute to the unique features of each disaster. To learn lessons from disasters it is important to recognise commonalities while being aware of that which is unique, or specific to the location. Researchers and emergency managers do this by recognising the special circumstances of each catastrophe and identify those factors as part of the explanation. There are many examples in studies of previous disasters that identify both those factors that are common and those which are unique.

For example Keys (2005), reporting on the 2002 floods in Germany and the Czech Republic identified the dismantling of former warning mechanisms and changing land management systems as an emergency management issue that could be transferred to the Australian experience, but at the same time he was impressed by the scale of the disaster which gave it its unique characteristics. Bankoff's (2003) assessment of flooding in the Philippines also recognises environmental problems, alongside the complexity of social and environmental factors, but he reduces the uniqueness to the social construction of vulnerability. Both writers stress the importance of 
understanding historical changes and processes to understand current hazards, but bring quite different perspectives on the nature of society.

The perspective brought by the researcher to a disaster event configures the lessons that may be learned and transmitted. Emergency managers are particularly involved in organisation and the political system. The limited number of questions and surveys that are available to researchers result in specific selections. Prater and Wu's (2002) study of Taiwan's 1999 earthquake was oriented to analysis of organisational and institutional responses. Similarly Wachtendorf's (2000) study of the Red River flood positively emphasised cross border political arrangements; in this instance the US/ Canada border. Betts (2003) on the other hand found institutional failings in flood warning systems in Victoria. The research perspective was from the bottom-up community level. Wachtendorf's was much more a view from the top down. Where researchers stand, or come from, influences the issues seen and the lessons learnt. This does not mean that one view is wrong and another right. All are real reflections of disastrous events, but the lesson that is learned is perhaps less from the event than from the observer. Pfister's (2002) assessment of Grafton's floods in 2001 identified a poor response to evacuation warnings and concluded a need for better warning education. As an emergency manager, this observation is Pfister's role and the correct view of community. However, community workers in southern India, Thomalla and Schmuck (2004) observed a similar sort of community response in Orissa in 1999 and concluded failures in government and NGO organisations as well as in the communities themselves. However, an overview of two decades of hazard research in southern India by Winchester (2000) concluded that NGOs had been effective but the crucial need was to target the poor who make up the bulk of the victims.

Many post-disaster studies examine post-traumatic stress, most are carried out by psychologists and psychiatrists and are often much more longitudinal in scope. Some emphasise the relief workers, others the victims. Johnes (2000) for example examined the impact of the Aberfan spoil heap collapse over 30 years after the event and Blatt (2001) subsequent to a mine disaster in Austria, both in order to assess failures in government and media that hampered recovery. The lessons learned were organisational although the emphasis was trauma. J onkman and Kelman (2005) identified inappropriate behaviour as a cause of flood deaths, and Gordon (2004), reflecting on a range of emergencies, concluded that social processes and relationships are drained and undermined during and following a disaster. The trauma and grief experienced by victims and survivors is not necessarily just a consequence of the actual hazard, but is constructed or exacerbated by other processes that are equally part of the disaster - organisational and social 
failings, the lopsided construction of the event by the media and a lack of appropriate knowledge.

Because a disaster is a terrible and destructive experience, researchers and emergency managers are invariably driven to find explanations as to why things went wrong in order to mitigate against future disasters. Postdisaster surveys and reflective papers can be expected to identify shortcomings. However, there is a significant category of positive analyses. These may broadly be put into groups of resilience and education. Recent resilience papers cover events of great diversity: destruction of the World Trade Center (Kendra \& Wachtendorf, 2003), recovery and sustainability in Kobe (Shaw \& Goda, 2004), community first aid response after the Northridge earthquake (Kano et al., 2005), social and ecological resilience (Adger et al., 2005), and emotional and psychological response and resilience following the Katherine floods of 1998 (Skertchly \& Skertchly, 2000). Handmer and Hillman (2004) also illustrate the importance of economic recovery in enhancing resilience following a range of Australian disasters.

Resilience is the key to learning from disasters. Studies that find flaws and organisational failings that have contributed to a disaster, stress vulnerability. At the community level when levels of impact and loss are identified it is clear which groups or locations in the community were the most vulnerable in a specific crisis. The outcome should then be a reduction of the vulnerability of those people and places. However, the things that make people vulnerable are often structural social issues. Poverty, ethnic isolation, infrastructural disadvantage, low levels of education, and such factors as complex as cultural practices and beliefs are areas of community vulnerability that are outside the control of the emergency manager.

While identifying factors of vulnerability to a disaster helps in understanding the process, these may not necessarily be the route by which vulnerability is reduced. By building on the resilience of society and strengthening positive factors, vulnerable communities may become more empowered to minimise the impact of future hazard events. Such empowerment mainly involves organisational and social change at the community level. Awareness and preparedness empower people to deal with their own situation and location. The two most direct influences on awareness and preparedness are direct experience and education. Education often begins with media accounts and images of disasters in other places - the news. News accounts initiate awareness, but awareness in itself can run into the arid wastes of fear, unless it is backed up by preparedness behaviour that is based on the strengths, capacity and resilience of communities. The media goes part of the way in taking some responsibility for preparedness by informing people of actions 
they can take, but shortcomings of media coverage are their needs for drama and for stories that are piecemeal and often not at all reflective of the real situation of a disaster. The media also lacks an interest in hazards when there is no immediate threat, unless this can be personalised by events like scientist and politician confrontations.

The greatest advantage of media coverage it is that it is potentially free education. Every other education and awareness campaign costs emergency management organisations money. However, a major inexpensive and highly effective route to awareness and preparedness action is through education in schools (Finnis et al., 2004; Izadkhah \& Hosseini, 2005). The effective cost of hazard education in school is a transfer of attention away from other subjects, but generally hazard modules are well integrated into social and environmental studies education. Apart from well taught hazards education being exciting and interesting to children, it is effective in laying down knowledge and action that may be absorbed by the child for life and which are also communicated to family, relatives and friends in the broader community through homework, projects and explanation.

Beyond the school, public awareness involves complex and costly strategies. O'Neil (2004) illustrates a range of individual social attitudes to hazards that may form the basis for specific targets and approaches of warnings and awareness campaigns. O'Neil's summary table below highlights different attitudes within the community.

\section{Table $3.2 \quad$ Hazard awareness targets}

\begin{tabular}{|l|l|l|}
\hline \multirow{3}{*}{ Risk averse } & $\begin{array}{l}\text { Concerned with the same } \\
\text { hazard as the agency }\end{array}$ & $\begin{array}{l}\text { Target this group with hazard specific } \\
\text { information \& messages \& focus on how } \\
\text { they will manage their response to the risk } \\
\text { (i.e. what to do in a cyclone) }\end{array}$ \\
\cline { 2 - 4 } & $\begin{array}{l}\text { Concerned with different } \\
\text { hazards to the agency }\end{array}$ & $\begin{array}{l}\text { Target this group with non-hazard specific } \\
\text { safety initiatives (What to do in an } \\
\text { emergency) } \\
\text { Agency partnerships }\end{array}$ \\
\hline Risk tolerant & $\begin{array}{l}\text { Ambivalent about the } \\
\text { hazard or the effect upon } \\
\text { them }\end{array}$ & $\begin{array}{l}\text { Target this group with general information } \\
\text { about the hazard. Highlight the risk from } \\
\text { the hazard and how it will affect their } \\
\text { family. }\end{array}$ \\
\hline Risk deniers & $\begin{array}{l}\text { Denies that the hazard will } \\
\text { occur or that it will affect } \\
\text { them. }\end{array}$ & $\begin{array}{l}\text { Target this group with messages that build } \\
\text { the credibility and authority of the agency. }\end{array}$ \\
$\begin{array}{l}\text { Sees a disaster as an } \\
\text { opportunity to become } \\
\text { involved in rescue efforts or } \\
\text { to pursue their interests }\end{array}$ & $\begin{array}{l}\text { During event, warn of dangers \& penalties } \\
\text { for interfering with work of emergency } \\
\text { agencies. After the event target with } \\
\text { specific messages relating to safety for } \\
\text { individuals and families. }\end{array}$ \\
\hline
\end{tabular}

Source: O’Neil, 2004 
Research into disaster impact on communities shows clearly that direct experience of a disaster is a particularly powerful awareness education event (Paton et al., 2001; Comstock \& Mallonee, 2005; Anderson-Berry \& King, 2005). It is common sense to expect hazard impacted communities to have developed greater awareness and to have responded by adopting appropriate preparations. Research shows that this happens as predicted, but not to such a high level as might be expected. The average community response is greater, but direct experience of a disaster does not transform all people into active community emergency managers. Rather, it results in a significant improvement in awareness and preparedness that may reduce, but not eliminate vulnerability to future hazards. Perhaps acceptance of people's limitations and an ability to respond appropriately to a crisis are resilience characteristics that communities rely upon.

\section{Conclusion}

Understanding, constructing and moving on to improved preparation are processes in learning from disasters that are influenced by a kind of distance decay effect. Distance decay is a gravity model (based on Newton's law of gravity) in which the influence of another place upon any given place is contingent upon the size of the other place and its distance away. This influence may be measured in such processes as migration or trade and flow of goods. Disasters outside our local community influence us in the same way. The further away the event is, the bigger it has to be to attract our attention. In distance decay models (used in human geography and economics) there are controlling elements in the formula, such as a factor of distance and a global constant. Qualifying factors are consequently things like the type of disaster, and the information technology. The community that experiences regular flooding or cyclones, pays greater attention to similar events elsewhere because of the commonality of experience, and would be much less interested in earthquakes or volcanoes. Yet, as shown above, the experiences of different disaster types can be transferred in terms of knowledge and experience. The Indian Ocean Tsunami demonstrated impacts that could be transferred to storm surge, as well as the general vulnerability of the coastal zone, tourists, critical infrastructure and buildings. The other qualifying factor, information technology, means that well-connected places are more visible. Researchers learn far more of hurricanes in the southern United States than of cyclones in much closer areas such as India and the Philippines because of the more ubiquitous technology and media of the developed world.

With these qualifying factors modifying the level of knowledge of other disasters, the basic rule is that the further an event is from our location the less is learnt about it or less attention paid, unless it is bigger, more 
spectacular, deadly or destructive. Therefore the following disaster learning problems can be summarised in relation to households and communities:

- There is the lack of transfer of knowledge and awareness between different types of hazards;

- Information technology gives emphasis to places, and events, that are better connected;

- Distant events that are learnt about are the biggest, and in a sense, the easiest to ignore because they are extreme;

- Most information is received on the most local events that, most of the time, are not extreme disasters - thus communities remain unprepared for a truly catastrophic event.

Consequently most communities receive hazard knowledge that reinforces complacency. Most disaster declarations experienced by most communities have not involved absolute devastation. Other local events are similar and communities being essentially resilient, they muddle through, prepare moderately well for survivable events and are further reinforced in their lower-level awareness. This is quite acceptable for the regular and predictable hazards that cause sufficient damage and disruption to warrant a disaster declaration, but do not result in devastation or significant loss of life. Unfortunately the distance decay effect reinforces the community view that terrible things happen a long way away, that our hazards are part of the way of life and the pattern of the seasons, and locals cope reasonably well. Thus until the terrible disaster happens locally, most people learn only selected lessons from other disasters. Communities are completely unprepared for the catastrophic disaster even when, as in New Orleans in 2005, they knew how vulnerable they really were. 